\title{
Geothermal Water in Lebanon: An Alternative Energy Source
}

\author{
Amin Shaban \\ National Council for Scientific Research, Remote Sensing Center, Beirut, Lebanon. \\ Email: geoamin@cnrs.edu.lb
}

Received August 23 ${ }^{\text {rd }}, 2010$; revised August 31 ${ }^{\text {st }}, 2010$; accept September $6^{\text {th }}, 2010$.

\begin{abstract}
Recently, demand for energy has been increased worldwide, notably in the view of high economic value and competition of fossil fuel, as well as the negative impact of fuel consumption through carbon release, and thus the consequences on human health and environment. Various aspects of energy sources into Earth's crust have been discovered and utilized. Geothermal energy is one aspect of these sources where they have been well pronounced in many countries and proved to be a potential energy source for the future needs. Lebanon, the country with rare natural energy, the renewable energy sources are almost ignored and there is only limited utilization of hydro-power, wind and solar energy, whilst oil imports occupy a substantial portion for energy use. Yet, geothermal energy has not raised and no concern has been given to this renewable source. Meanwhile, there are several indicators showing the existence of geothermal water in different regions in Lebanon. They almost occur where basalt rocks are exposed. This was evidenced whether from water in drilled wells or from various discharging springs, as well as indications of thermal water was observed also in many localities along the Lebanese coastal water. This study shows the available information in this respect, considering the occurrence of geothermal water in Lebanon as an alternative energy source. Thus four major geothermal domains were recognized. The study introduces detailed characterization on the existing aspects of geothermal water and inducing its hydrologic regime and mechanism of groundwater heating. It would be a reconnaissance stage that may help applying further detailed assessment.
\end{abstract}

Keywords: Hot Water, Springs, Alternative Source, Lebanon

\section{Introduction}

Energy has become an utmost need for human life and any shortage in energy supply will result a serious national problem, notably with the increase of population size that accompanied with high standard of living. This in turn motivated many countries to search for alternative energy sources other than fossil fuel, which is a depleted source and often results negative environmental aspects. Recently, the geothermal energy has become one aspect of these alternatives. Rough estimates indicated that geothermal energy can cover the world's need of energy for the next 100000 years [1]. This is well pronounced in the United States where geothermal energy is supposed to supply $10 \%$ of electricity needs by the year 2050 .

Even though, almost everywhere in the upper 10 feet of the Earth's surface maintains a nearly constant temperature between $10^{\circ} \mathrm{C}$ and $16^{\circ} \mathrm{C}$, yet there is higher heat that released from deep Earth and composing a renewable sort of energy, which is a clean and sustainable resource that occurs at depths everywhere beneath the Earth's surface and ranges from few meters in certain areas to a few kilometers ( 5 to $8 \mathrm{~km}$ ) beneath the Earth's surface and reaches down even deeper to the extremely high temperatures of molten rock called magma.

There are several potential uses for geothermal energy, but it is mainly used to heat buildings, as well as in generate electricity. While, the exploitation procedure implies drilling wells into underground reservoirs. In this regard, there are several techniques used to tap geothermal sources, and it mainly involves injecting cold water down into wells, circulating it through hot fractured rocks, and drawing off the heated water from another well. Currently, this technology is still with less commercial benefits. The existing technology also does not allow recovery of heat directly from magma, the very deep and powerful source of geothermal energy.

Lebanon, the Middle Eastern country with relatively small area $\left(\sim 10400 \mathrm{~km}^{2}\right)$, lacks to local energy sources, and demand for renewable energy has been exacerbated. 
For this reason, Lebanon imports around $\$ 500$ million worth of fuel annually to generate the electricity needs [2] and yet there is a shortage in electrical power supply. In addition, there are no studies to assure the existence of potential fossil fuel for energy generation, except few prospects, such as those on uranium [3].

There are several aspects of renewable energy sources that can be utilized in Lebanon. These are attributed, in a broad sense, to hydro-power, wind, solar and geothermal energy. Hydro-power sources have been used in Lebanon since few decades, such as that in Qaraoun Lake in the Bekka region, but they neither implemented over wide geographic areas nor developed to fulfill their power as an integral source for energy. While, wind and solar energy are almost applied on limited and local basis, since they do not follow a strategic plan with wide range of application. Therefore, oil products are still the principal energy source in Lebanon and they compose about $93.5 \%$ of energy supply according to obtained estimates in 2003 (Figure 1).

Yet, there is no concern to the geothermal energy in Lebanon and studies on this respect are still rare except brief mentioning the existence of this source in many articles $[2,4,5]$. Meanwhile, there are many observations of natural hot water in different localities on the Lebanese territory, likewise many other observations on the neighboring countries, such as in Syria and Jordan. However, no detailed investigation has been done to interpret their hydrological regime, and then to induce how they can be exploited.

There is no hydrological or geophysical investigations applied in Lebanon in order to verify the existence of geothermal water. The known observations imply spontaneously (naturally) evidenced phenomenon of hot water discharge either in springs or water wells. Many of the known hot water (and sometimes warm water) discharges were existed in places where igneous rocks (almost basalt and tuff) are exposed, but this is not always the case and some of them occur in the proximity of basaltic rocks too.

The major objective of this study is to characterize the existing geothermal water sources, which are represented by hot and warm water, with a special emphasis on the geological and hydrological setting where they exist. This will help identifying the major geologic elements governing the flow regime of geothermal water, thus identifying their hydrologic controls, which help indicating the existence of new geothermal sources in different places in Lebanon. This in turn motivates applying further studies with detailed investigation, which may lead to create a strategic plan for geothermal water exploitation in Lebanon.

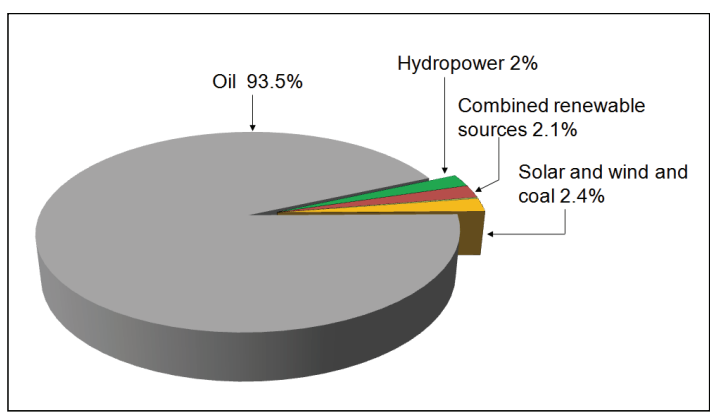

Figure 1. Primary energy supply in Lebanon in 2003 (adapted from ALMEE, 2005 [6]).

\section{Indicators of Geothermal Water}

Indicators of geothermal water sources in Lebanon imply both surface water and groundwater in different localities and at various levels on/or in the proximity of the basalt rock exposures. The identified sources were indicated by inhabitants, as well as they depend on mentions in previous studies. They can be attributed, in a broad sense, to:

\subsection{Springs}

In Akkar region, north Lebanon along the Syrian border where large basaltic rock plateau exposed (Figure 2), there are several observations for hot/or warm water from springs and seepages at different localities. Many of them show low discharge, which is almost less than $1 \mathrm{l} / \mathrm{sec}$; therefore, most of these springs and seeps were dried as a result of overexploitation of groundwater, and also due to the ignorance of these sources by local community. Yet, one these springs remain and called "AinEsamak" spring. However, it is totally ignored and has not been properly utilized. Filed testing shows that the average temperature of this spring ranges between $50-65^{\circ} \mathrm{C}$ over various time periods.

\subsection{Off-Shore Springs}

The hydrologic phenomenon of hot and warm water is not limited to the terrestrial environment, but also it extends to the marine environment where some off-shore hot springs were identified by fishermen along the Lebanese coastal zone. These off-shore springs were identified at three sites, one along the southern coast beside city of Tyre $\left(33^{\circ} 15^{\prime} 33^{\prime \prime} \& 35^{\circ} 11^{\prime} 32^{\prime \prime}\right)$, and the other two in the north, adjacent to A'abdeh (343 $\left.31^{\prime} 37^{\prime \prime} \& 35^{\circ} 59^{\prime} 07^{\prime \prime}\right)$ and Chekka (34 $\left.19^{\prime} 24^{\prime \prime} \& 35^{\circ} 43^{\prime} 21^{\prime \prime}\right)$ regions (Figure 2). The first one (near Tyre) occurs as thermal vents in sea floor at a distance of about $300 \mathrm{~m}$ from the coast and at a depth of about $30 \mathrm{~m}$. These vents were distributed on an area of about $800 \mathrm{~m}$. In addition other smaller vents in the seafloor were observed by fishermen. However, the 


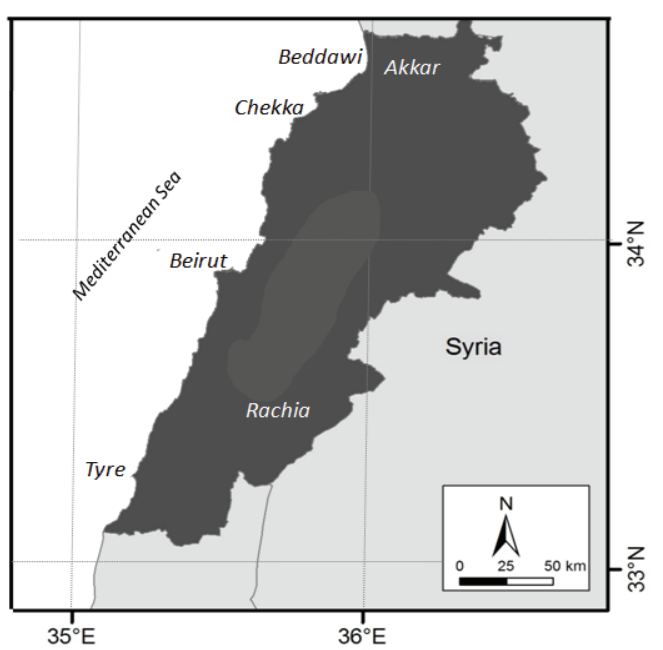

Figure 2. Map of Lebanon showing the sites of known geothermal water.

actual temperatures were not estimated.

The other two were springs were detected during an airborne Thermal Infrared survey when they appear as dissipated clusters of small bubbles (few centimeters in diameter) at a distance from the coast [7]). The temperature of these clusters was about $38^{\circ} \mathrm{C}$ while the surrounding temperature of water was about $26^{\circ} \mathrm{C}$.

\subsection{Groundwater}

Hot and warm groundwater has been noticed in several drilled wells in Lebanon. This is well pronounced in wells dug into/or near hard and fractured basaltic rocks and some of them were found in the carbonate rocks (i.e. dolomite and limestone). However, the latter are almost occur with lower temperature than those in basalt, and the heat was decreased after pumping in many of these wells, which also showed temperate steams, injected along wells' tubes.

This phenomenon has been witnessed in Akkar region in the north as well as in Sohmor and Kaoukaba and ElGhajar in south (Figure 2). Whereas, the most known well was drilled in Akkar in 1970s to a depth of approximately $550 \mathrm{~m}$ in the fractured basalts, thus water was injected due to the high piezometric pressure to about 30 above ground. The measured temperature of water was $70^{\circ} \mathrm{C}$ and it contained high content of sulfur [2].

\section{Materials and Method}

Based on the criteria that volcanic rocks are the major source of heat to result geothermal water, thus studying the geology of these rocks must be primarily considered in order to induce the relationship between rock structures and lithology with respect to hot water. Hence, the rock succession of Lebanon shows three principal intervening media of basaltic irruption among different sedimentary stratum. These are in the Middle Jurassic, between Late Jurassic and Early Cretaceous as well as in the Pliocene age [8]. Even though, basalt is the major igneous rock type in these levels, yet each of them has different mineralogical characteristics and even their vertical delineation and geographic distribution have various aspects and dimensions.

From a geological point of view, the igneous rocks which are related to relatively recent volcanic eruptions are most considered for the geothermal water sources, since their activity is supposed to be still existing [5]. This is well evidenced since all the existing geothermal water was in/or nearby the Pliocene basalt. Therefore, in the case of Lebanon, Pliocene rock exposures are utmost important to investigate the geothermal water, and for this reason they were tackled in this study.

In accordance with the objective of the study; however, three principal steps were followed:

1) Identifying the geographic distribution of basalt exposures

2) Filed survey and geochemical analysis whenever it was accessible

3) Identifying the hydrological controls for geothermal water.

Identifying the location of geothermal water sources, with respect to the geological formations and rock structures, was the principal task to be done. For this purpose, geological maps (1:50.000 scale) obtained by Dubertret [9] were utilized. Hence, geological field measures were taken (e.g. bedding planes inclination, strata superposition, lithological characteristics, etc) and thus lithological cross-sections and illustrations of rock successions were applied whenever it was needed. This was accompanied with filed investigation to assure the reliability of information on the known geothermal water sources, whether in terrestrial and marine springs as well as for geothermal water in the observed wells. Therefore, direct measurements for the temperature were taken. Consequently, sampling procedures were carried out whenever it was accessible in several sources for further geochemical analysis on the selected sources.

The identified sources were diagnosed in order to understand the geologic setting where they exist, and thus to induce any relationship with the local hydrology. In the light of this scope, maps of rock fractures were also used to figure out the mechanism of water heating and flow regime. For this purpose satellite images, such as Aster images with $15 \mathrm{~m}$ resolution (Figure 3), were utilized since they are capable to lithologies and fractures properly. 


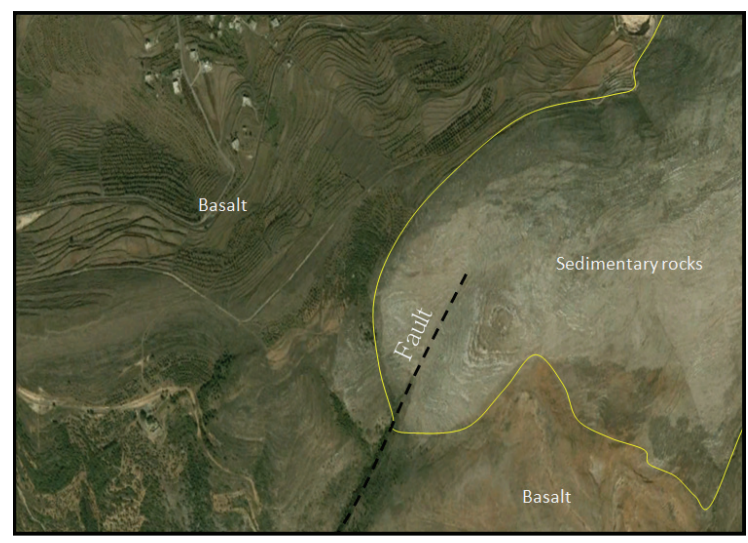

Figure 3. Identification of basalts from Aster images.

\section{Results}

\subsection{Geographic Distribution of Basalt}

The geographic distribution of basalts was identified primarily from the available geologic maps as well as they were checked in a field survey, which was carried out on different localities around the basaltic exposures. Thus, basalts with tuffaceous materials of the Pliocene were attributed to four major domains where they are widely spread. They exist in the regions of: Akkar, Hinayder, Kaoukaba and El-Ghajar (Figure 4). Since the study concerns with geothermal water sources; however, these domains were described as geothermal domains. These domains were investigated using the available geological maps in combination with filed verification to selected sites on the basaltic exposures, thus the major specifications of these domains were summarized (Table 1).

The geographic distribution of basalt exposures in these domains can be attributed mainly to the volcanic eruptions along lava veins, dikes and faults, in addition to local fracture systems. Their thickness and spatial extent at different localities and levels indicates the existence of volcanic activity in the Pliocene age $(<2$ million years $)$, which points out to the probability of further lava veins and similar geothermal water in other localities in the region.

\subsection{Geochemistry of Geothermal Water}

The topic on geothermal water in Lebanon is still at the reconnaissance stage, and concerns are not given to induce a potential use of this source. Hence, there is no any existing exploitation procedure of geothermal water. For this reason, geochemical sampling was not properly accessible to apply detailed investigation, such as deep sampling from wells to measure the geothermal gradient and other geochemical properties. Therefore, the geochemistry in this study was carried out depending on the accessibility

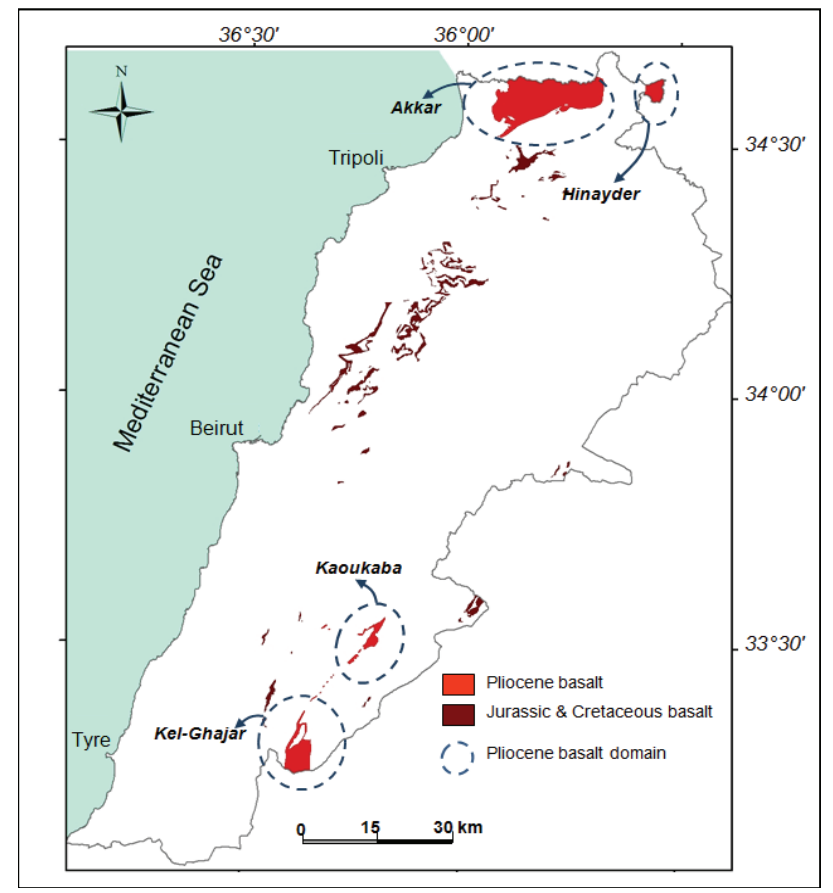

Figure 4. Distribution of basalts in Lebanon.

of water sampling; in particular it was applied to AinEsamak spring in Akkar, the off-shore sources in Chekka region and to water well in Koukaba region. Thus, measures were obtained on temperature, $\mathrm{pH}$ and salinity (TDS). Results show high carbonate and sulphate contents as well as remarkable $\mathrm{pH}$ and temperature (Table 2).

According to Bahati et al. [10], the geothermal fluids are characterized by high carbonate and sulphate constants and salinity of 19000 to $28000 \mathrm{mg} / \mathrm{kg}$ total dissolved solids.

\subsection{Hydrology of Geothermal Water}

In order to diagnose the hydrology of geothermal water, geological controls (e.g. fractures, veins, rock bed inclination, etc) must be primarily identified. This will help recognizing the mechanism of heating and flow regime of hot water, as well as proposing new geothermal sources. This was applied, in particular, to characterize the stratification of different lithologies and their contact with basalt rock masses, as well as in the basalt rocks themselves. In addition, structure systems were investigated to induce any existing hydrologic correlation.

In this respect, the four geothermal domains were studied and their geologic and hydrologic characteristics were determined. For this scope, filed survey was carried out, thus illustrations and cross sections were established.

In general, the geologic setting of the existing Pliocene basalts in Lebanon constitutes a volcanic lava flow regime. 
Table 1. Major basalt domains in Lebanon and their specifications.

\begin{tabular}{|c|c|c|c|c|c|}
\hline \multirow{2}{*}{$\begin{array}{l}\text { Geothermal } \\
\text { domain }\end{array}$} & \multicolumn{2}{|c|}{ Coordinates* } & \multirow{2}{*}{-Area $\uparrow\left(\mathrm{km}^{2}\right)$} & \multirow{2}{*}{$\begin{array}{l}\text { Average } \\
\text { altitude } \\
(\text { m.a.sl) }\end{array}$} & \multirow{2}{*}{ Basalt characteristics } \\
\hline & Latitude & Longitude & & & \\
\hline Akkar & $34^{\circ} 35^{\prime} 15^{\prime \prime}$ & $36^{\circ} 08^{\prime} 55^{\prime \prime}$ & 135 & $400-450$ & $\begin{array}{l}\text { - Massive basaltic plateau dominant with fracture } \\
\text { systems, } \\
\text { - Syenite and tuff occur in different localities and at } \\
\text { different levels } \\
\text { - Fluid inclusions appear as internal and external } \\
\text { vascular pits, } \\
\text { - Rose-basalt and calcite veins are common. } \\
\text { - Basaltic, syenite and tuff occur at various levels, }\end{array}$ \\
\hline Hinayder & $34^{\circ} 36^{\prime} 50^{\prime \prime}$ & $36^{\circ} 25^{\prime} 50^{\prime \prime}$ & 24 & $500-550$ & $\begin{array}{l}\text { - Surficila fluid inclusions are common, } \\
\text { - Laval flow is featuring in several sites. }\end{array}$ \\
\hline Kaoukaba & $33^{\circ} 23^{\prime} 40^{\prime \prime}$ & $35^{\circ} 38^{\prime} 50^{\prime \prime}$ & 17 & $550-600$ & $\begin{array}{l}\text { - Block basaltic lava with fumaroles } \\
\text { - Fracture systems, mainly jointing is dominant } \\
\text { - Massive and boulder basalts, } \\
\text { - Vertical joint and fracture systems are well de- }\end{array}$ \\
\hline El-Ghajar & $33^{\circ} 16^{\prime} 20^{\prime \prime}$ & $35^{\circ} 37^{\prime} 30^{\prime \prime}$ & 33 & $300-325$ & $\begin{array}{l}\text { veloped, } \\
\text { - Calcite and iron veins exist, } \\
\text { - Empty vascular cylindrical veins occur. }\end{array}$ \\
\hline
\end{tabular}

${ }^{*}$ Coordinates in the mid-point area; ${ }^{\dagger}$ Area within Lebanon.

Table 2. Major geochemical measures of selected geothermal water in Lebanon.

\begin{tabular}{cccc}
\hline Thermal source & Temperature & TDS & pH \\
\hline Ain-Esamak & $65{ }^{\circ} \mathrm{C}$ & $21000 \mathrm{mg} / \mathrm{kg}$ & 8.3 \\
Chekka off-shore sources & $38^{\circ} \mathrm{C}$ & $18500 \mathrm{mg} / \mathrm{kg}$ & 7.7 \\
Koukaba region well & $35^{\circ} \mathrm{C}$ & $16000 \mathrm{mg} / \mathrm{kg}$ & 7.4 \\
\hline
\end{tabular}

Thus, four interrelations were identified as follows:

- Occurrence of massive basalt plateaus (e.g. Akkar, Hinayder and El-Ghajar domains)

- Lava flow widely erupted among the carbonate rocks of the Cenomanian limestone rock formation (e.g. Akkar and Hinayder domains)

- Lava flow erupted along the Cenomanian and Jurassic carbonates (e.g. El-Ghajar domain)

- Lava flow erupted among or Cenomanian and related laying formations (e.g. Kaoukaba domain).

Therefore, the internal heat affects the groundwater and results geothermal water following two mechanisms:

- Heating within the basalt rock masses, which are characterized by intensive fracture systems (i.e. recharge zone), thus high permeability and porosity occur. The percolated (recharged) water into fractures was subjected to heat transfer from deep molten materials (Figure 5(a)). This might not be occurred unless the magma is shallow enough to heat directly the basalt.

- Contact heating between the basalt rock masses and the adjacent carbonate rocks, which are almost of fractured and karstified limestone and dolomite aquifers (Figure 5(b)).

Accordingly, the existence of geothermal seepages and springs on terrain surface is attributed principally to the existing fault and fissure systems (Figure 5(b)), such as the case of the NE-SW trending faults between Bire and Mantara in Akkar region along which the geothermal source of Ain Esamak is located. There is also a similar fault that trends in the NE-SW direction and intersect along Er-Rafid and Kfer Mishka in Kaoukaba region. These faults compose geothermal fracture zones, which is a widely hydrologic phenomenon worldwide, likewise those occur in Turkey and having similar characteristics as Lebanon [11].

Some of the intersecting faults between the basalt and the carbonate rocks have considerable length that exceeds several tens of kilometers and reach the sea floor, as indicated from satellite images [12]. This in turn interprets the existence of geothermal water in the marine environment facing A'abdeh, Chekka and Tyre.

\section{Conclusions and Discussions}

Energy sources are not usually occurred spontaneously on terrain surface to indicating their existence, but they usually be discovered everywhere by human by applying several methods of investigation. Hence, looking for alternative energy sources must be considered and given attention as much as the current usable sources. This must be applied to Lebanon the country with a great need to have alternative energy sources, notably in the light of 


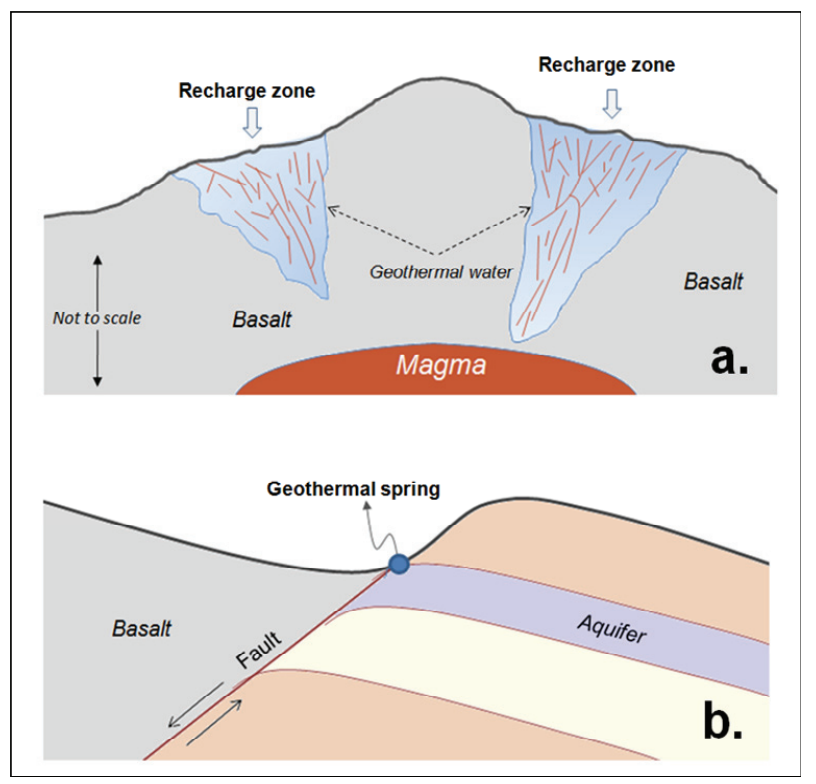

Figure 5. Schematic figures showing various hydrology of geothermal water source.

the existing physical and anthropogenic factors. This can be achieved if strategic plans for natural resources assessment are applied.

A surveillance and research studies, such as the current study, are utmost important. In Lebanon, other than hydro-power, wind and solar energy which are being limitedly utilized as well as the currently discussed oil exploration; however, geothermal energy must be considered, especially by the governmental sectors.

There are many indicators on the geothermal water sources in Lebanon, and they occur in various hydrologic aspects, which were tackled in this study. Yet, there is no detailed information on these sources. This study is an empirical attempt to characterize the existing sources and to put the first hand information on the geologic and hydrologic setting of the geothermal water in Lebanon. It discusses the mechanism of groundwater heating in order to yield geothermal water.

Based on the hydrologic controls in this study, it is obvious that geothermal groundwater in Lebanon is an existing source. It is also evidenced and anticipated to be existed on other sites where the Pliocene basalts are located with similar hydrologic properties. Therefore, the potential localities for geothermal water in Lebanon can be reached by drilling a number of wells on/near the basalt rock masses considering the following hydrological elements:

1) Fault alignments are potential sites for geothermal water, in particular along fault contacts between basalt masses and sedimentary rock sequences. This can be applied to the three trending faults mentioned previously in Akkar, Kaoukaba and El-Ghajar regions.

2) Fracture zones, and more certainly fissure systems, are also promising sites for geothermal water, but only those fissures occurred within the Pliocene basalt body masses and not the sedimentary ones.

3) Deep sedimentary groundwater basins (i.e. aquiferous rock formations) that are located in a close proximity to Pliocene basalts are also potential for geothermal water sources, but a number of hydrogeological elements must be taken into account (e.g. hydraulic gradient, strata inclination, etc).

In addition, the existing geothermal sources must be reinvestigated and then plans for exploitation must be put. Such as the Ain Esamak spring, which must be rehabilitated, as well as all geothermal seeps and hot/warm water appears in wells must be investigated in depth. Moreover, the hydrologic conduits that transporting hot water to the sea should be also delineated in order to determine their sources on-land.

\section{REFERENCES}

[1] AEC, American Energy Commission, 2006. http://www1. eere.energy.gov/geothermal/history.html

[2] A. Houri, "Renewable Energy Sources in Lebanon: Practical Applications," ISESCO Science and Technology Vision, Vol. 1, 2005, pp. 65-68.

[3] A. Shaban, "Geological Prospects for Uranium Deposits in Lebanon," Environmental Hydrology Journal, Vol. 16, Paper 12, 2008.

[4] GLA, "Status and Potentials of Renewable Energy Technologies in Lebanon and the Region (Egypt, Jordan, Palestine, Syria)," Desk Study Complied by Green Line Association, 2007.

[5] A. Shaban, "The Geo-Thermal Energy in Lebanon," Technical Report (In Arabic), CNRS, 2009, p. 10.

[6] ALMEE, "State of Energy in Lebanon," Association libanaise pour la maitrise de l'energi at l'environnement, 2005. http://www.Almee.org/pdf/state\%20of\%20the $20 \%$ energy\%20Lebanon.pdf

[7] LCNRS, Lebanese National Council for Scientific Research, "Thermal Infrared Survey to Detect Submarine Springs along the Lebanese Coast," Technical Report, 1999, p. 33.

[8] Z. Beydoun, "Petroleum Prospects of Lebanon: Reevaluation," American Association of Petroleum Geologists, Vol. 61, No. 1, 1977, pp. 43-64.

[9] L. Dubertret, "Carte géologique de la Syrie et du Liban au 1/200000me," 21 feuilles avec notices explicatrices, Ministère des Travaux Publics, L'imprimerie Catholique, Beyrouth, 1955, p. 74.

[10] G. Bahati and F. Natukunda, "Status of Geothermal Exploration and Development in Uganda," Short Course III on the Exploration of Geothermal Resources, Kenya, 2008, p. 10.

[11] U. Serpen, "Hydrogeological Investigations on Balcova 
Geothermal System in Turkey," Geothermic, Vol. 33, No. 3, 2004, pp. 309-335.

[12] A. Shaban, M. Khawlie, C. Abdallah and G. Faour, "Geo- logic Controls of Submarine Groundwater Discharge: Application of Remote Sensing to North Lebanon," Environmental Geology, Vol. 47, No. 4, 2005, pp. 512-522. 